University of Montana

ScholarWorks at University of Montana

\title{
Charting a Course With NOMAP: Integrating Metadata Workflows Into a Traditional Cataloging Unit
}

Teressa M. Keenan

University of Montana - Missoula, teressa.keenan@umontana.edu

Follow this and additional works at: https://scholarworks.umt.edu/ml_pubs

Part of the Library and Information Science Commons

Let us know how access to this document benefits you.

\section{Recommended Citation}

Teressa M. Keenan (2012) Charting a Course With NOMAP: Integrating Metadata Workflows Into a Traditional Cataloging Unit, Journal of Library Metadata, 12:2-3, 199-212, DOI: 10.1080/

19386389.2012.699842

This Article is brought to you for free and open access by the Mansfield Library at ScholarWorks at University of Montana. It has been accepted for inclusion in Mansfield Library Faculty Publications by an authorized administrator of ScholarWorks at University of Montana. For more information, please contact scholarworks@mso.umt.edu. 


\title{
Charting a Course With NOMAP: Integrating Metadata Workflows Into a Traditional Cataloging Unit
}

\author{
TERESSA M. KEENAN \\ Maureen and Mike Mansfield Library, The University of Montana, Missoula, Montana, USA
}

\begin{abstract}
The life of a cataloger today is in a state offlux; as libraries continue to transition from a predominately print world to a digital one, catalogers need to secure a functional future. To do so catalogers must change their mental models to stay flexible and pertinent in an ever-changing information environment. A recent digital project undertaken at the University of Montana provides an example of bow research and developments in the area of metadata and bibliographic control have influenced cataloging and metadata workflow integration.
\end{abstract}

KEYWORDS case study, cataloging, metadata, project management, workflows

Cataloging workflows are in a state of flux as libraries continue to transition from a predominately print world to a more digital world. Catalogers can no longer simply rely on the Anglo-American Cataloguing Rules, Second Edition revised (AACR2rev) for guidance; they must now choose between AACR2rev, Resource Description and Access (RDA) and a host of other metadata schemas such as Dublin Core (DC), Metadata Encoding and Transmission Standard (METS), Metadata Object Description Schema (MODS), Encoded Archives Description (EAD), etc. Additionally, catalogers now need to be aware of and understand the difference between metadata schema, or rules, and syntax. While syntax has not always been clearly differentiated from data entry, nor has its importance been consistently highlighted in the mind of the traditional cataloger, it is, nevertheless, essential to creating useable data. Proper encoding allows the data to be understood and processed by a computer. To secure a functional future, catalogers must change their 
mental models and develop their skills to allow them to work with multiple encoding schemes such as Machine Readable Cataloging (MARC), Resource Description Framework (RDF), eXtensible Markup Language (XML), and Hyper-Text Markup Language (HTML). A recent digital project undertaken at the University of Montana provides an example of how research and developments in the area of metadata and bibliographic control have influenced cataloging and metadata workflow integration in the real world.

During the summer of 2009, the Maureen and Mike Mansfield Library (ML) joined forces with Native American scholars to provide access to previously identified resources pertaining to the indigenous peoples of Montana. Led by Dr. David Beck, professor and chair of the Native American Studies Program (NAS) at the University of Montana, and Dr. JoAllyn Archambault, director of the Native American Program at the National Museum of Natural History, Smithsonian Institution, the Natives of Montana Archival Project (NOMAP), ${ }^{1}$ is a collaborative project to collect primary source documents related to the various tribes of Montana. Collections from the National Archives, National Museum of Natural History, and the Smithsonian were targeted with the intention of making them digitally accessible to researchers without direct access to the original physical documents.

Prior to the library's involvement, NAS researchers used the Southwest Oregon Research Project (SWORP) as a model (Southwest Oregon Research Project, 2006; Younker, 2009). An inventory of major archival collections and a key word identifier index were created. This research uncovered more than two million relevant documents within a single record group at the National Archives (RG 75 CCF 1907-1939). From this work a priority list for coordinating the digitization of the original documents was created. The digital-collections librarian then worked with a team of graduate students to establish best practices and to provide training in the use of cameras and software. The students traveled to Washington, DC, and spent a month taking digital photos of the original documents. Raw images were saved to an external portable hard drive, which was then sent to the library. Library staff and faculty provided post-processing of the digital images, metadata creation, and public access to the digitized materials.

To date there have been more than 35,000 documents digitized, all of which are hosted on the Montana Memory Project, Montana's Digital Library and Archives web site (MMP). ${ }^{2}$ The library portion of the project has been split into three phases, each phase requiring approximately a year to complete. Future phases are contingent upon continued funding. Phase 1 consisted of approximately 13,000 images collected in 2009 (published in 2010). Phase 2 involved collecting more than 22,000 images during the summer of 2010 (published in 2011). Phase 3 is in process with metadata currently being completed for the approximately 19,000 images collected during the summer of 2011 (publication expected in spring 2012).

Prior to implementing a plan for integrating metadata creation into the workflow of traditional copy catalogers, relevant literature was consulted in 
an effort to gain guidance in assimilating new concepts and practices into established routines. Presentations by researchers about future directions in metadata (Coyle, 2010d) combined with research on the expansion of cataloging to include digital objects (Riemer, 2010) were helpful in providing context for the incorporation of metadata into Bibliographic Management Services (BMS). While research on the Semantic Web and the future of cataloging were thought provoking and provided a theoretical background for project planning and for establishing a basis for explaining the jobpriority changes to staff, actual case studies such as those conducted at the Georgia Institute of Technology Library (Hudgins \& Macklin, 2000) provided a better framework for establishing local workflows and creating training opportunities.

Literature on future directions for metadata clearly indicates that libraries need to take a different approach to maintaining the data that is available to them, suggesting that data needs to be used, reused, and shared openly (Coyle, 2010a, 2010b, 2010c; Hartig, Zhao, \& Mühleisen, 2010; Knight, n.d.; Zeng et al., 2010). However, not all libraries are in a position to follow such a course at this point in time. Small- to medium-sized organizations without the financial and intellectual resources to restructure their legacy data and that rely on "out-of-the-box" software for presentation and preservation of digital collections may have to postpone updating their library's infrastructure to accommodate a system of linked data. Current cataloging research corroborates this fact by pointing out that "converting legacy metadata to linked data will require a team of experts, including MARC-based catalogers, specialists in other metadata schemas, software developers, and Semantic Web experts to design and test normalization/conversion algorithms, develop new schemas, and prepare individual records for automated conversion" (Bowen, 2010). That same research, however, also provides reassurance that such changes are possible and that tools and standards are being developed that will assist all libraries in the future (Bowen, 2010; Hartig et al., 2010). Because of these continuing developments, libraries should monitor current best practices when embarking on new projects in an effort to make future data conversion as straightforward as possible.

The amount of literature that addresses the integration of non-MARC metadata functions into the workflow of traditional catalogers is continuing to grow. Much of this literature focuses on the benefits of involving catalogers in metadata functions and the need to keep skills of technical services personnel current and competitive (Feltner-Reichert \& Veve, 2007; Hudgins \& Macklin, 2000; Riemer, 2010). Other studies focus on the perceptions of catalogers (Feltner-Reichert \& Veve, 2007; Veve \& Feltner-Reichert, 2010), and some provide detailed descriptions of preparation and training necessary for the integration of non-MARC metadata into traditional cataloging workflows (Feltner-Reichert \& Veve, 2007; Hudgins \& Macklin, 2000; Valentino, 2010). 


\section{THE SETTING}

The University of Montana (UM) is a multicampus university with four affiliated campuses located in Dillon, Helena, Butte, and Missoula. The Missoula campus is a satellite College of Technology (COT). UM is a medium sized coeducational, doctoral institution and is classified as a research university. Established in 1895, the Maureen and Mike Mansfield Library (ML) serves a student population of more than 14,000. ML holds the largest collection of books and media in the state of Montana with collections exceeding 1.5 million volumes. ML also serves as the Federal Government Depository for the state. Over the last 10 years, ML has increased access to electronic literature and now has more than 30,000 journals (print and electronic), hundreds of electronic databases, and 77,000 electronic books (Mansfield Library Collection Development Group, 2011).

Within the last five years, ML has begun to develop and build digital collections, making more than 114,000 digital objects available to the public. Digitization takes place within both the Archives and Special Collections Department and the Bibliographic Management Services Department (BMS). BMS provides all of the acquisitions, cataloging, and processing of library materials for ML and COT. BMS comprises 13 paraprofessional staff and two professional faculty organized in teams based on primary work focus. Five staff members focus on acquisitions and copy cataloging monographs and media; two focus on acquisitions and access for serials and e-resources; five staff members focus on cataloging (monographs, media, serials, music, maps, and government documents); and one staff member focuses on digitization. The head of BMS is one of two professional catalogers in the department. The administrator/cataloger's time is split between administering the unit and providing original cataloging and metadata guidance. The responsibilities of the other professional cataloger include original cataloging and oversight of acquisitions and e-resource processes.

\section{NOMAP AND INTEGRATING METADATA}

Integration of metadata creation into the workflows of copy catalogers within BMS has been an evolving process. Each phase of the NOMAP digitization project incorporated additional personnel into the general workflow. Figure 1 illustrates the changes in workflow as the project evolved.

\section{Phase I}

Phase 1 of this project was completed without the involvement of BMS staff. The digital projects librarian worked closely with individual faculty and graduate students from NAS to ensure adherence to current best practices for 

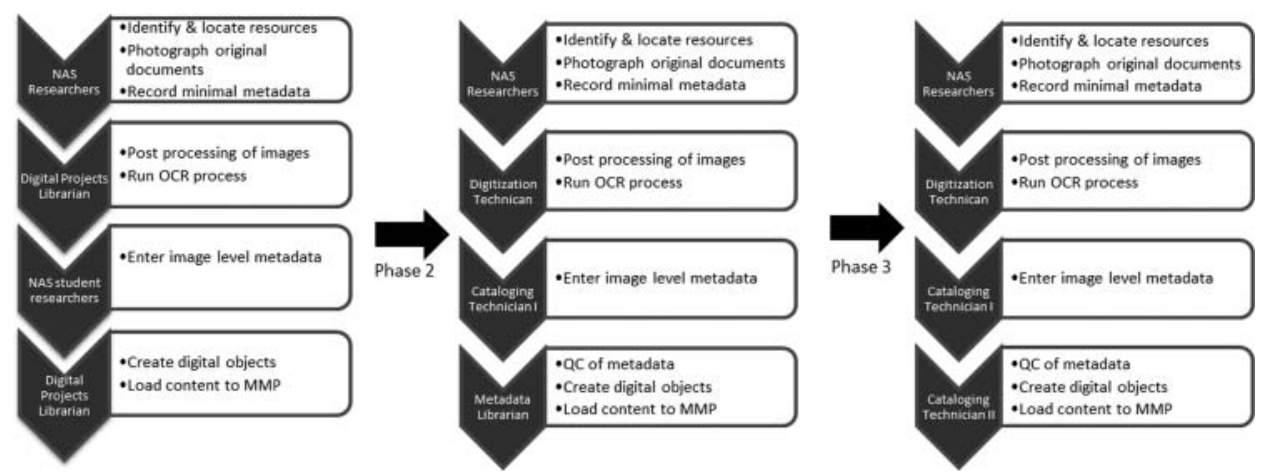

FIGURE 1 Illustration of workflow changes through each phase of the project.

digitization of the original materials. He assisted with training and provided all the post-processing of the raw images into a useable format for distribution. Working with NAS students and faculty, the metadata librarian subsequently determined that dates, names, and geographic locations were the metadata elements of primary importance to the researchers. Research about metadata quality and issues related to management and access of digital assets provided guidance in the creation of an application profile ${ }^{3}$ that would work within the parameters of the software/presentation platform (CONTENTdm) currently in use by the library, while still providing for concerns by project stakeholders. Additional research on quality control of metadata stressed the importance of accuracy and consistency in metadata creation (Chapman, Reynolds, \& Shreeves, 2009; Park, 2009; Park \& Tosaka, 2010) and provided guidance in planning for training and reviewing the work.

The metadata librarian provided one of the NAS graduate students with an introduction to Dublin Core and an overview of how to record the data in Microsoft Excel in order for it to be transferrable to CONTENTdm. The librarian emphasized the importance of consistency in data entry. Figure 2 presents a portion of the Excel spreadsheet used by the student to record metadata. After the metadata were created, the digital projects librarian established the collection within MMP, matched the metadata to the appropriate image files, and loaded all of the digital objects to CONTENTdm. While this approach to the project worked, it was obvious to both the metadata librarian and the digital-projects librarian upon final review that the process was not scalable and that improvements were needed to enhance and ensure the quality of the metadata. Moreover, the expectation of the acquisition of a larger number of images during phase II suggested that additional personnel would be needed to provide metadata creation within a reasonable time frame. Producing metadata as part of the regular operations of BMS would also make the most of the skilled expertise of catalogers. Using controlled vocabularies for names and subject headings, combined with the natural 


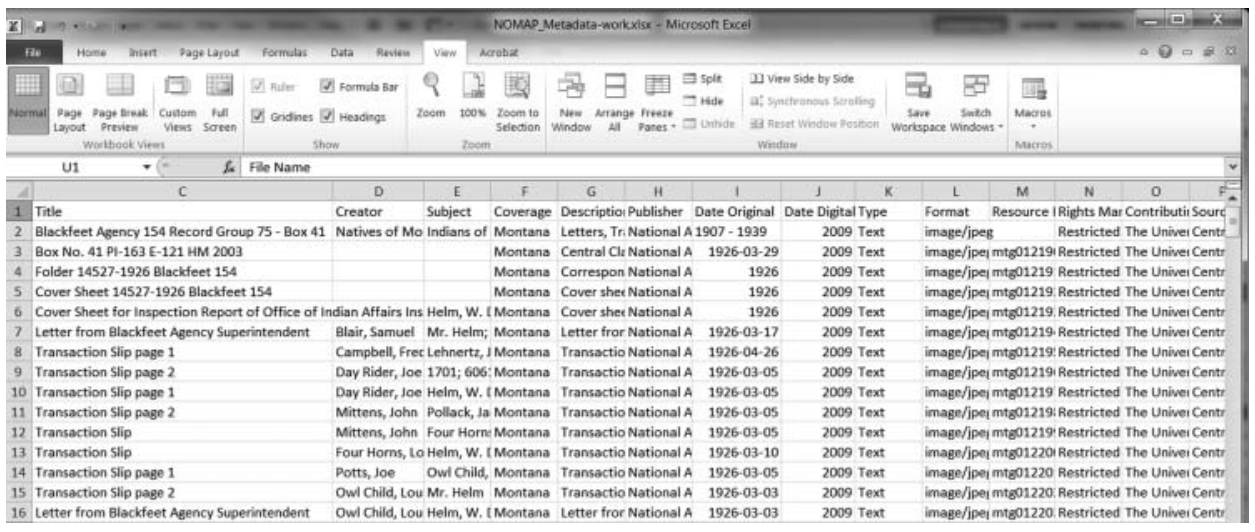

FIGURE 2 Illustration of a portion of the Excel spreadsheet used to record metadata during phase I of the project.

language keywords already being entered would provide better overall access to the collection.

\section{Phase II}

While the NAS students were in Washington, DC, collecting new digital images, library staff in BMS were introduced to the project. The general background and goals were shared, and a call for volunteers was issued. A majority of individuals within the department expressed interest in participating in the project. A group training session was scheduled to introduce staff to Dublin Core in general and to the application profile and workflow for the NOMAP project specifically. Instructions and reference resources were added to a wiki, ${ }^{4}$ providing a centralized location for tracking all aspects of the project.

Prior to staff involvement with NOMAP, a smaller digitization project involving newspapers provided the opportunity for volunteers to practice their new skills applying descriptive metadata to digital objects using the rules associated with the Dublin Core element set. Additional training was provided to specifically address entering metadata for this project. Eleven paraprofessional staff from the department participated in the initial metadata training, and ten participated in creating metadata for the newspaper project.

This smaller project used Microsoft Excel as a tool for compiling metadata. While Excel is a common tool used by specialists outside the library, catalogers do not generally have the same level of comfort working with the program (Valentino, 2010). Our experience verified this with the local population as well. Much time was spent by the metadata librarian with troubleshooting, training, and quality control of data entered into the Excel spreadsheet. To alleviate this issue for the NOMAP project, the metadata librarian worked closely with systems staff to create an Access database. The 


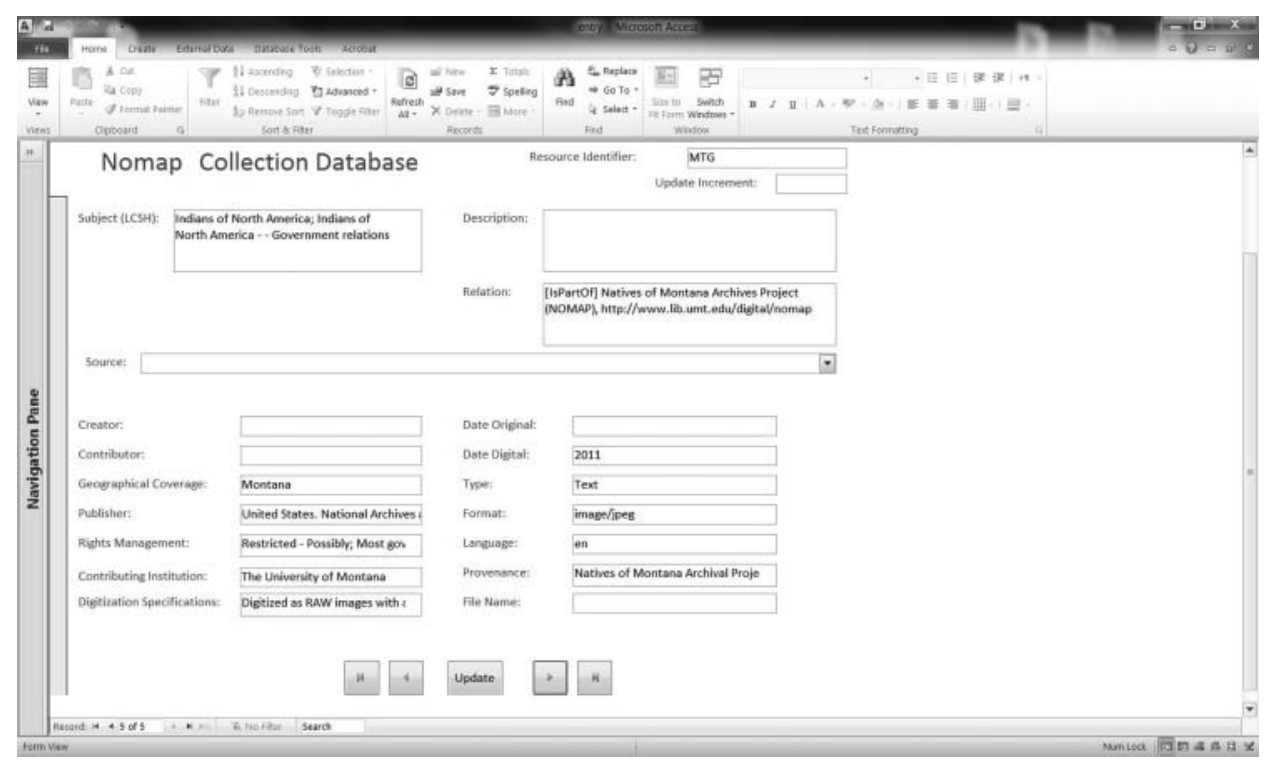

FIGURE 3 Example of the data entry form used by catalogers to record metadata into Access during phase II of the project. Default data is prepopulated in the form to increase efficiency and accuracy.

development of a data entry form (Figure 3) allowed catalogers to input metadata without having to learn the intricacies of the computer program in order to successfully complete the project.

Creation of the database was complicated by the fact that multiple individuals could potentially be working on the project at the same time. A master database was created and stored on the network, and individual databases were copied and loaded onto each cataloger's computer. A macro automatically transferred the data from an individual's hard drive to the master database upon completion of each data input session. An additional macro allowed information in the master database to be updated if changes were made to previously entered data. Training sessions for the catalogers were then scheduled to review the Dublin Core elements and to provide an introduction to entering the metadata via the new form. Of the eleven paraprofessional staff that attended the original training, eight worked on the project on a volunteer basis.

While periodic troubleshooting and review of the use of the Access form was needed at the beginning of phase II, until staff became comfortable using the new interface, this process was much more successful than using Excel for data entry as had been done with the newspaper project workflow. Once the metadata entry was completed by cataloging staff members, the metadata librarian used queries to retrieve and collocate the data and then export it to an Excel spreadsheet. The data were reviewed for quality control, and additional information was added to the spreadsheet to create the structure 
of the digital object. The final step by the metadata librarian involved loading the material into CONTENTdm for public access.

\section{Phase III}

After phase II and prior to the beginning of phase III of the project, cataloging staff was asked to review the data entry process. An informal discussion group was formed consisting of five of the paraprofessional catalogers and the metadata librarian. The Access form was modified and improved based on the suggestions made by the discussion group. Data that are often repeated were carried through from one image entry to the next, and dropdown menus (Figure 4) were added to improve consistency and ease of entry.

Because of the changes to the form and the fact that almost four months had passed since completion of phase II, instruction sessions were set up to provide general review of Dublin Core and to specifically examine common errors or problems discovered during the quality control process of phase

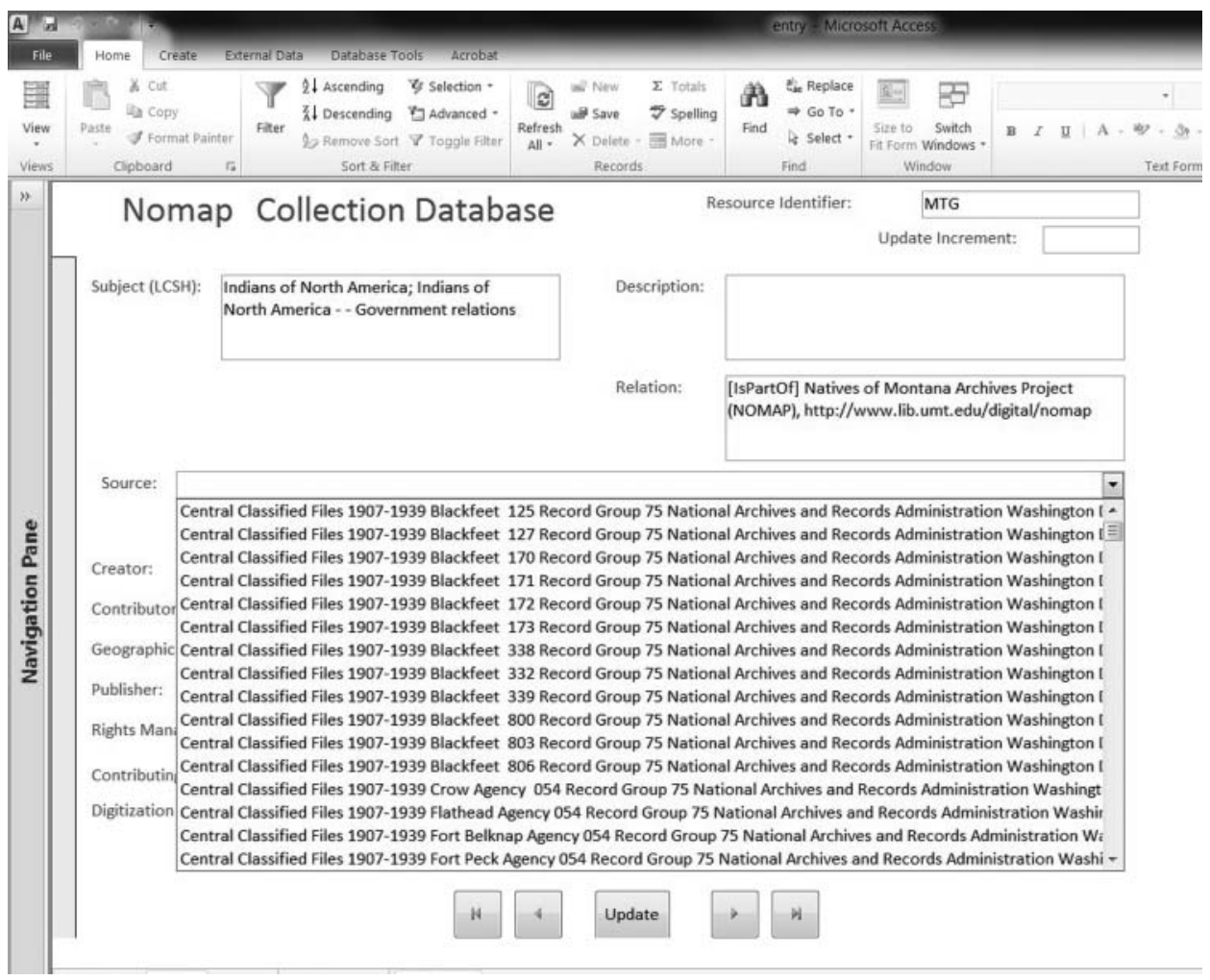

FIGURE 4 Screenshot of the dropdown menu that was added to the form for the source field prior to beginning phase III. 
II. At the time of writing, six paraprofessional catalogers continue to create image-level metadata for this project, with the expectation that the digital objects will be publicly available in the spring. Preliminary quality control and ongoing discussions of the workflow with staff indicate that results are slightly better than phase II results. The staff is more comfortable with the Dublin Core element set and the revised Access form interface is leading to faster input and fewer errors. In particular, the use of the dropdown menus and the capability to auto-fill certain data elements has obviated some of the more common input errors encountered in phase II.

\section{HURDLES AND SOLUTIONS}

While the initial excitement and number of volunteers for the project was encouraging from a management prospective, a few obstacles needed to be overcome in order to seamlessly integrate metadata assignments into the normal workflows of the department.

\section{Time, Productivity, and Perceptions}

In spite of the large number of volunteers, it was evident that for phase II to be completed on schedule staff would need to dedicate more time to the project. A volunteer-only system was not producing the desired results. As with most organizations, the staff in the BMS department has a variety of tasks to perform. Adding the metadata creation to that list does not reduce the amount of traditional cataloging the staff is responsible for on a daily basis. Even with all the good intentions of the volunteers to work on the project, individuals felt they did not have the time to dedicate to the metadata entry. Informal discussions among staff members and comments by staff members to supervisors indicated that some believed the traditional cataloging responsibilities were a higher priority than were the new non-MARC metadata assignments. Thus the work was not progressing on the expected schedule.

In an effort to assuage this problem, catalogers and management worked together to improve the plan in action, resulting in better incorporation of metadata into traditional cataloging operations. Current trends in cataloging and libraries were described to staff and the overall goals of the project timeline were reviewed. Position descriptions were reviewed and updated to specify metadata as a regular job responsibility for four of the paraprofessional cataloging technicians. They were then asked to split their cataloging time equally between traditional MARC and non-MARC metadata work. Emphasis was placed on the fact that the expected result of this would be increased output of digital objects and reduced output of physical materials. This is part of the mindset that must change for catalogers to continue to have a functional future (i.e., that traditional cataloging is not necessarily 
our highest priority any more.) Catalogers may have to be flexible with priorities and reduce productivity in one area in order to increase it in another. Administrators and managers must also support this kind of flexibility.

In addition to the perception that non-MARC functions should take a back seat to MARC cataloging, informal remarks from staff indicated that there was a general feeling of inadequacy in regard to the use of Dublin Core. Some individuals felt that the metadata work was of a lower quality than they normally produced. Catalogers were used to following the AACR2rev. and MARC21 encoding at a much more granular level than was required of Dublin Core and the local application profile for the project. In order to assuage these types of concerns, management must communicate the end goals of the project, the difference between the standards, and why one standard is chosen over another. Professionals who are spearheading these types of projects need to be aware that these perceptions exist and work to help cataloging staff understand that their cataloging and indexing expertise is a valued component to the successful completion of any digitization project. Project managers need to highlight the fact that the schema and encoding schemes used will vary by project and catalogers must expect to be working with multiple options for best practice standards. Perhaps most important, project managers must emphasize that the work that catalogers do is still just as important as ever in providing access to resources.

\section{Teaching New Skills}

In addition to time management and clear expectations of productivity, effective training is essential. In completing the NOMAP project, it soon became apparent that the original group training would not be sufficient for complete integration of metadata into traditional workflows. Because of a wide variety in skills, education, and comfort with new technologies among staff, a more individualized approach to training was needed; some staff needed additional review and practice with the metadata while others needed to build general computer skills.

Four key staff members were identified as lead workers based on their advanced cataloging skills. It was thought that a strong understanding of AACR2 and cataloging practice would benefit individuals in learning the differences between traditional cataloging and creating metadata following standards such as Dublin Core. However, the reality was that a strong understanding of AACR2 both helps and hinders the process of transitioning to using multiple standards. It provided a shared context from which to base conversations and training; however, it was difficult for some staff to move from one standard to another. Habits developed over years of cataloging may be difficult to modify. One example involved confusion over the appropriate location for geographic information. Staff wanted to include geographic information in the subject field of a Dublin Core record just as 
they had traditionally done in the 650 field of a MARC21 record instead of exclusively in the Dublin Core geographic coverage field. A second example involved splitting out information that traditionally would be included in subfields of a single field such as the publisher information found in the 260 field of a bibliographic record encoded in MARC21. Rather than placing the publisher in one field and date information in another field, catalogers included delimiters and subfield codes into metadata fields, which were then not translated correctly by CONTENTdm. It became evident that training needed to provide more emphasis on distinguishing the difference between rules, syntax, and encoding. A better understanding of how these separate concepts work together to create access to a resource made it easier for catalogers to transition from one set of standards to another. Additional conversations with staff during regular cataloging meetings about the theory behind the use of Dublin Core brought to light that, while the concepts were understood, it was more difficult than expected to adapt to new cataloging procedures.

Furthermore, a strong understanding of AACR2 and traditional cataloging protocols did not guarantee comfort with working in a variety of computer interfaces. Computer skills and comfort varied widely, even among the four lead staff members assigned to the project. Review of file structure and naming, sorting principles, and the difference between local versus network drives was necessary for everyone to work effectively. Although the data entry form created by the System Department allowed staff to enter data with limited knowledge of Microsoft Access, some background in database structure and specific training on how to use the form was necessary. Most of this training needed to be done on an individual basis because of the differences in comfort and competence with computer applications among the staff. For some training was as simple as providing a reminder to click the update button so changes and/or additions would be included in the master database, while for others a more in-depth explanation of what a database is and the difference between storing information on their local computer versus a shared server was needed.

\section{CONCLUSIONS}

Overall, the outcome of the NOMAP project has been a success. Research materials were digitized and made available to the public. Work has been completed within the established timeline and budget allotted. At the completion of each phase of the project, workflows have been evaluated and redesigned to better integrate metadata creation into the general workflow of traditional cataloging within the department. Lessons have been learned that transcend the specific example of NOMAP and provide a foundation for future digital projects. 
While the details of this case study will be of interest to other organizations that are looking for ways to modify existing or create new digital project workflows, lessons learned from this study have implications beyond that of general workflow design. NOMAP significantly impacted managers and staff in the technical services department of UM's Mansfield Library, and changes in philosophies and procedures have evolved in response to those lessons.

NOMAP project managers learned that clear direction to employees (catalogers) as to the goals of the project, time frames, and the mechanics of creating the metadata are essential. Managers must anticipate staff weaknesses and provide training where necessary within the constraints of budgets. The training can be a combination of educational opportunities, including one-on-one instruction, in-house seminars, webinars, or out-oflibrary short courses. Managers must also consider the necessity to keep moving forward with traditional cataloging and processing. They must determine the optimum balance between working with traditional materials and creating new metadata and clearly transmit their expectations to staff.

The NOMAP project demonstrated that staff members have different levels of comfort and competence with both the cataloging and the computer skills required to incorporate metadata creation into their workflows. An essential component of adding metadata to staff workflows was communicating the expectation that staff understand the changing nature of cataloging work and that they must be flexible and learn both new skills and how to apply existing skills to new situations. The atmosphere in technical services must be such that individual staff members are encouraged to review their own skill sets and communicate to their managers what skill sets need updating through additional training.

As part of the analysis of the skills required for projects such as NOMAP, managers and administrators must review the workflows related to digitization and metadata and assign responsibilities to optimize staff resources. For example, allowing the digitization technician and student employees to focus on technical aspects of creating and managing image files and relying on catalogers to add metadata allowed the library to make best use of the skills and abilities of personnel. From a broader perspective, the result of this analysis may be modification of the skill sets required for new employees. Graphic design, data structure, and experience with relational databases are becoming just as important to potential catalogers as are attention to detail and an understanding of cataloging and indexing.

Perhaps the most important lesson learned is that the incorporation of digital projects into the library's workflow is an evolving process. Minor modifications to the workflow may still be made based on lessons learned with phase III of NOMAP. For example, one recent minor modification to the project workflow is to inform the catalogers by email when a portion of the project has been added to MMP to encourage them to view the final product. 
The hope is that seeing the end product will help them better envision what their efforts have produced and perhaps even formulate ideas as to how they might modify workflows to produce a better result.

Continued examination of various workflows and methods of integrating metadata into traditional cataloging departments of all sizes is needed. As libraries begin to transition to a system of linked data and digital collections, new tools are being developed that will assist with the creation, manipulation, and preservation of data. New models of information organization are being scrutinized and catalogers are learning new ways in which to apply their skills. Continued exploration and acceptance of these and other unforeseen changes will ensure a functional future for catalogers in the digital age.

\section{ACKNOWLEDGMENTS}

The author would like to express her sincere thanks to Marian Lankston, from the University of Montana, for her valuable suggestions during the writing of an earlier version of this paper. The author is also grateful to the reviewers of the Journal of Library Metadata for their useful comments.

\section{NOTES}

1. Natives of Montana Archival Project (NOMAP): http://www.lib.umt.edu/digital/nomap

2. Montana Memory Project, Montana's Digital Library and Archives web site: http://cdm16013. contentdm.oclc.org:80/, UM-Natives of Montana Archival project collection: http://cdm16013.contentdm. oclc.org/cdm/landingpage/collection/p15018coll44

3. The application profile that was created for NOMAP can be downloaded from the project documentation section of the library's digital projects wiki: http://wiki.umt.edu/library_digital/ index.php/NOMAPS_Project_Documentation\#Metadata_.2F_Data_Directories_.2F_Application_Profiles

4. NOMAP Instructions and Resources wiki: http://wiki.umt.edu/library_digital/index.php/ NOMAPS_Instructions_\%26_Resources

\section{REFERENCES}

Bowen, J. (2010). Moving library metadata toward linked data: Opportunities provided by the eXtensible Catalog. Proceedings of the 2010 International Conference on Dublin Core and Metadata Applications, DCMI '10 (pp. 44-59). Retrieved from http://dl.acm.org/citation.cfm?id=1891793.1891799

Chapman, J. W., Reynolds, D., \& Shreeves, S. A. (2009). Repository metadata: Approaches and challenges. Cataloging \& Classification Quarterly, 47, 309-325. doi:10.1080/01639370902735020

Coyle, K. (2010a). Chapter 1: Library data in the web world. Library Technology Reports, 46(2), 5-11.

Coyle, K. (2010b). Chapter 2: Metadata models of the World Wide Web. Library Technology Reports, 46(2), 12-19.

Coyle, K. (2010c). Understanding the semantic web: Bibliographic data and metadata. Chicago, IL: ALA TechSource. 
Coyle, K. (2010d, April 2). Archive: Directions in metadata webinar. ALA TechSource. Retrieved from http://www.alatechsource.org/blog/2010/04/archive-directionsin-metadata-webinar.html

Feltner-Reichert, M., \& Veve, M. (2007, June 23). Integrating non-MARC metadata into a traditional technical services department: Perspectives from librarians at the University of Tennessee Libraries. Presented at the ALA Annual, Washington, DC. Retrieved from http://library.wichita.edu/techserv/CatNorms/Integrating_ Non-MARC_Metadata.pdf

Hartig, O., Zhao, J., \& Mühleisen, H. (2010, May). Automatic integration of metadata into the web of linked data. Demo presented at SPOT 2010 at the 2nd Workshop on Trust and Privacy on the Social and Semantic Web, Heraklion, Greece.

Hudgins, J., \& Macklin, L. A. (2000). New materials, new processes: Implementing digital imaging projects into existing workflow. Library Collections, Acquisitions, and Technical Services, 24(2), 189-204. doi:10.1016/S1464-9055(00)00129-9

Knight, F. T. (n.d.). Break on through to the other side: The library and linked data. SSRN eLibrary. Retrieved from http://papers.ssrn.com/sol3/papers.cfm? abstract_id $=1815487$

Mansfield Library Collection Development Group. (2011, May). Collection development policy. Retrieved from http://www.lib.umt.edu/files/MansfieldLibrary_Collection-Development-Policy-2011-05.pdf

Park, J.-R. (2009). Metadata quality in digital repositories: A survey of the current state of the art. Cataloging \& Classification Quarterly, 47, 213-228. doi:10.1080/01639370902737240

Park, J.-R., \& Tosaka, Y. (2010). Metadata quality control in digital repositories and collections: Criteria, semantics, and mechanisms. Cataloging \& Classification Quarterly, 48, 696-715. doi:10.1080/01639374.2010.508711

Riemer, J. J. (2010). The expansion of cataloging to cover the digital object landscape. Cataloging \& Classification Quarterly, 48, 551-560. doi:10.1080/01639374.2010.496309

Southwest Oregon Research Project. (2006). Guide to the Southwest Oregon Research Project (SWORP) Collection 1850-1950. NWDA. Retrieved from http://nwda-db.wsulibs.wsu.edu/findaid/ark:/80444/xv14723

Valentino, M. L. (2010). Integrating metadata creation into catalog workflow. Cataloging \& Classification Quarterly, 48, 541-550. doi:10.1080/01639374. 2010.496304

Veve, M., \& Feltner-Reichert, M. (2010). Integrating non-MARC metadata duties into the workflow of traditional catalogers: A survey of trends and perceptions among catalogers in four discussion lists. Technical Services Quarterly, 27(2), 194-213. doi:10.1080/07317130903585477

Younker, J. T. (2009). Southwest Oregon Research Project: A model for large scale Native American archival reconnaissance missions. Washington, DC: Native American Program, National Museum of Natural History Smithsonian Institution.

Zeng, M. L., Needleman, M., Oh, S., Phipps, J., Summers, E., Deridder, J., \& Hodge, G. (2010). Linked data-Enabling standards and other approaches. Proceedings of the American Society for Information Science and Technology, 47(1), 1-2. doi:10.1002/meet.14504701053 